\title{
A subjetividade às avessas: toyotismo e "captura" da subjetividade do trabalho pelo capital
}

\author{
Giovanni Antonio Pinto Alves ${ }^{1}$ \\ Universidade Estadual Paulista
}

\begin{abstract}
O objetivo do ensaio é desvelar os mecanismos internos da lógica do toyotismo como nova ideologia orgânica do controle da força de trabalho e do trabalho vivo no capitalismo global. O toyotismo torna a exploração do capital mais consensual, envolvente e manipulatória. A constituição dos novos consentimentos espúrios exigidos pelo método toyota ocorre por um intenso processo de manipulação da subjetividade do trabalho vivo (que é o conteúdo da "captura" da subjetividade). A lógica manipulatória do toyotismo sob o lastro das inovações sócio-metabólicas atinge as dimensões do psiquismo humano. Apresentamos os conceitos de "inconsciente estendido" e "compressão psico-corporal" como lastro categoriais explicativos importantes da nova dinâmica psicossocial do capitalismo manipulatório.
\end{abstract}

Palavras-chave: Trabalho, Toyotismo, Capitalismo global, Psicanálise, Estresse.

Toyotism and the "capture" of subjectivity of labour on global capitalism

Our objective is to watch the internal mechanisms of the logic of the toyotism as new organic ideology of the control of the manpower in the global capitalism. The toyotism turns the exploration of the capital more consensual, involving, and manipulatory. The constitution of the new spurious consents demanded by the toyota method happens for an intense process of manipulation of the subjectivity of the work (that is the content of the "capture" of the subjectivity). The manipulatory logic of the toyotism under the ballast of the partner-metabolic innovations reaches the dimensions of the human psyche. We present the concepts of "extended unconscious" and "psycocorporal compression" as important explanatory categories of the new social-psychologic dynamics of the global capitalism.

Keywords: Work, Capitalism, Toyotism, Global capitalism, Psychoanalysis, Stress.

$\mathrm{O}$

toyotismo, como salientou Ricardo Antunes, implica uma lógica "mais consensual, mais envolvente, mais participativa, em verdade mais manipulatória" (Antunes, 1995). Neste ensaio, nosso objetivo é desvelar os mecanismos internos da lógica do toyotismo que a torna mais consensual, envolvente e manipulatória. A constituição dos novos consentimentos espúrios exigidos pelo método toyota ocorre por um intenso processo de manipulação da subjetividade do trabalho vivo (que é o conteúdo da "captura" da subjetividade). A lógica manipulatória do toyotismo sob o lastro das inovações sócio-metabólicas atinge as dimensões do psiquismo humano. É o que buscaremos desvelar ao tratar do significado de subjetividade humana.

Nosso objetivo é apenas indicar hipóteses provisórias de trabalho, sem nenhuma pretensão de desenvolvê-las, nem muito menos esgotá-las. Pelo contrário, o que se coloca hoje, mais do que nunca, é a necessidade de constituir uma teoria marxista da "subjetividade", tendo em vista que o nexo essencial da ideologia orgânica da produção do capital tornou-se a "captura" da subjetividade/intersubjetividade do trabalho.

Ao tratarmos de alguns temas, as instâncias do psiquismo humano e a teoria do inconsciente, não iremos nos deter em explanar as controvérsias em torno da teoria freudiana, um debate rico que foge a nossas pretensões imediatas. Mais uma vez, reiteramos que, o que

1 Departamento de Sociologia e Antropologia da Faculdade de Filosofia e Ciências da UNESP, campus de Marília. 
colocamos neste ensaio é uma agenda de investigação que pode articular campos multidisciplinares numa perspectiva crítica capaz de desvendar os mecanismos ocultos dos consentimentos espúrios que sedimentam a ordem sócio-metabólica do capital, principalmente no que diz respeito à hegemonia do capital na produção.

Ao tratarmos do problema da subjetividade humana tivemos que fazer uma opção teórico-metodológica pela psicanálise, deixando de lado as teorias psicológicas que tratam da personalidade e subjetividade humana. Consideramos a psicanálise, a ciência da subjetividade burguesa, capaz de contribuir para a apreensão das dimensões ocultas da alma burguesa. A contribuição dada por Sigmund Freud ao conhecimento científico do homem é indiscutível. Apesar dos limites apontados por uma série de autores, as categorias freudianas não deixaram de ser reconhecidas como de inestimável valor heurístico para desvendar as contradições do metabolismo social da civilização burguesa. Por isso, as categorias freudianas, na medida em que são apropriadas de forma crítica, são importantes para a apreensão da dinâmica subjetiva da individualidade de classe que surge com a civilização do capital (não nos compete discutir neste momento, a ampla controvérsia que surge no marxismo do século XX sobre o valor $\mathrm{e}$ significado da psicanálise) $)^{2}$.

A tripartição do psiquismo humano que utilizamos é de origem freudiana, sendo elaborado por Freud na sua primeira tópica (1900-1920). Na primeira tópica, ou teoria dos lugares, ele definiu o aparelho psíquico como sendo constituído pelo inconsciente, o préconsciente e o consciente (na segunda tópica freudiana, nos escritos do 1920-1939, o pensador austríaco fez intervirem três instâncias ou três lugares, o id, o ego e o superego). Consideramos, a título meramente heurístico, a subjetividade humana composta por mente e corpo que, de modo indissociável, constituem a individualidade social. Na mente, segundo a ótica freudiana, distinguimos, como instâncias do psiquismo humano, a consciência, pré-consciência e inconsciente.

Portanto, ao tratarmos da subjetividade e de sua "captura", referimo-nos não apenas à instância da consciência, mas às instâncias da pré-consciência e do inconsciente. As técnicas de manipulação utilizadas pelos aparatos midiáticos do sistema do capital buscam atingir o conteúdo oculto da pré-consciência e do inconsciente humanos, visando a influenciar o comportamento dos indivíduos sociais. Na sociedade burguesa, como observaram Marx e Engels, a ideologia dominante é a ideologia da classe dominante, que constitui seus aparatos de dominação hegemônica pela manipulação midiática das instâncias pré-conscientes e inconscientes do psiquismo humano.

O capitalismo manipulatório levou à exaustão os recursos de manipulação das instâncias intrapsíquicas do homem, pelas quais se constituem os consentimentos espúrios à dominação do capital nas "sociedades democráticas". O sócio-metabolismo do capital ocorre por meio do tráfico de valores-fetiches, expectativas e utopias de mercado que incidem sobre as instâncias intrapsíquicas. $\mathrm{Na}$ medida em que o toyotismo baseia-se em atitudes e comportamentos pró-ativos, a construção do novo homem produtivo utiliza, com intensidade e amplitude, estratégias de subjetivação que implicam a manipulação incisiva da mente e do corpo por conteúdos ocultos e semi-ocultos das instâncias intrapsíquicas.

2 Em sua crítica do freudismo, publicada no livro O freudismo (de 1927), Mikhail Bakhtin, despreza o valor heurístico das categorias de Freud, reduzindo sua teoria a mera "psicologia subjetiva", que reduz a dinâmica psíquica às forças naturais, desprezando a dinâmica social e os fatores objetivos da dinâmica psíquica (Bakhtin, 2001) (outro psicólogo russo, Lev Vygotski, que desenvolve uma notável psicologia de base marxista, possui grandes afinidades com Bakhtin no tocante à critica do freudismo). Em 1927, o pensamento social, psicológico e filosófico na URSS já estava profundamente marcado por uma ideologia que condicionava todo comportamento social do homem exclusivamente à estrutura de classe da sociedade. O que Bakhtin talvez não consiga apreender é que o freudismo, como a economia política clássica, contém um "nódulo racional" que explica, mesmo que mistificada pelas incrustações da ideologia burguesa, a subjetividade da individualidade de classe imersa em formas de fetichismo e relações sociais estranhadas. A psicanálise de Freud é a economia política da subjetividade do homem burguês, "subjetividade em desefetivação", centrada nos motivos do ego e do self. Na verdade, o que se deve é elaborar uma superação dialético-materialista (aufheben, que significa superar/conservar) das categorias da psicanálise de Freud, sob pena de, como diz o ditado, "jogar fora o bebê junto com a água suja do banho". 
As habilidades comportamentais tornaram-se imprescindíveis no sistema toyota de produção. Ao tratar da profunda mudança nas qualificações exigidas para o novo trabalho industrial e de serviços na empresa toyotizada, Ana Teixeira observa:

Essa mudança poderia ser sintetizada como perda de importância das habilidades manuais em favor das habilidades cognitivas (leitura e interpretação dos dados formalizados; lógica funcional e sistêmica; abstração; dedução estatística; expressão oral, escrita e visual) e comportamentais (responsabilidade, lealdade e comprometimento; capacidade de argumentação; capacidade para trabalho em equipe; capacidade para iniciativa e autonomia; habilidade para negociação). Essas novas qualificações poderiam ser organizadas em três grandes grupos: novos conhecimentos práticos e teóricos; capacidade de abstração, decisão e comunicação; e qualidades relativas à responsabilidade, atenção e interesse pelo trabalho (Teixeira, 1998).

Ao privilegiar habilidades cognitivo-comportamentais, o método toyota é obrigado a imiscuir-se, como as estratégias de marketing, nas instâncias do psiquismo humano. Controlar atitudes comportamentais tornou-se a meta dos treinamentos empresariais, mobilizando valores-fetiches, expectativas e utopias de mercado, que atuam nas freqüências intrapsíquicas do inconsciente e do pré-consciente. Os consentimentos espúrios que compõem a hegemonia social do toyotismo têm na emulação pelo medo, um dos afetos regressivos da alma humana, um dos seus elementos cruciais. Aliás, o sócio-metabolismo da barbárie é uma "fábrica do medo" que, enquanto afeto regressivo que atua na instância do pré-consciente e do inconsciente, torna-se a "moeda de troca" dos consentimentos espúrios das individualidades de classe. A função estrutural da barbárie social é a produção simbólica do medo como afeto regressivo da alma humana.

A produção do capital é também produção (e negação) de subjetividades humanas. $O$ sócio-metabolismo do capital é constituído por processos de subjetivação que formam as individualidades de classe. Os tipos humanos, que a sociedade burguesa produz, forma e deforma, têm em si, na mente e no corpo, impressas a marca do fetichismo da mercadoria. A individualidade de classe, na medida em que é a negação da individualidade pessoal, tensiona ao limite de sua própria negação a subjetividade humana. É por isso que a história social e cultural da psicanálise foi marcada no século XX pelo problema do narcisismo, do ego ao self (Zaretsky, 2006).

$\mathrm{Na}$ verdade, a subjetividade humana imersa no metabolismo social do capital é uma "subjetividade em desefetivação", estressada pelas teias da manipulação social. Essa condição histórica da práxis social em sociedades do fetichismo da mercadoria coloca imensos desafios à "negação da negação". O fetichismo da mercadoria e a pletora de fetichismos sociais, que se constituem a partir dele, colocam constrangimentos cruciais à produção da subjetividade humana nas sociedades mercantis complexas. Na medida em que o capital é um sistema de controle do metabolismo social e, segundo Mészáros (2002), "uma poderosa, até o presente, de longe a mais poderosa - estrutura 'totalizadora' de controle do metabolismo social que surgiu no curso da história humana", ele instaura processos de subjetivação intrincavelmente paradoxais que, ao mesmo tempo que ampliam o templo da alma humana, dilaceram-na e limitam suas potencialidades humano-genéricas pela manipulação incisiva dos seus traços ontologicamente fundantes e fundamentais, como a linguagem e a capacidade simbólica do homem.

No plano da linguagem, a manipulação que surge a partir do novo complexo de reestruturação produtiva é indiscutível, com o surgimento do imperialismo simbólico e de novos léxicos que habitam o universo locucional das individualidades de classe. Além do aspecto ideopolítico, a utilização dos novos vocábulos no mundo do trabalho têm uma função psicossocial. Com Gramsci, diríamos que o "novo terreno ideológico" que nasce com o toyotismo é também uma nova "atitude psicológica" que "alimenta a afirmação da 'aparência' 
das superestruturas" (Gramsci, 1984b). A troca da nomeação "operários" ou "empregados" por "colaboradores" não é inocente (Ohno chamava as empresas fornecedoras de "empresas colaboradoras", ocultando a relação de poder contido na relação capital hegemon, do capital concentrado com os pequenos e médios capitais).

A mudança do universo léxico-locucional no mundo do trabalho deve ser analisada a partir das mudanças que ocorreram para que a sociedade contemporânea passasse a usar esse tipo de símbolo para falar de si mesma. Além de ser produto de uma práxis estranhada, é resposta a um fracasso que não podemos desconsiderar.

A saturação de signos e imagens no sistema de controle sócio-metabólico do capital coloca novos pressupostos materiais para a construção dos nexos psicofísicos do homem produtivo. Os processo de subjetivação (e dessubjetivação) ocorrem por meio de signos e imagens. Os conteúdos manipulatórios têm que assumir a forma de signos e imagens para instaurar os tráficos intrapsíquicos. Por isso, os valores-fetiches - expectativas e utopias de mercado que constituem as inovações sócio-metabólicas e compõem o nexo psicofísico do homem produtivo do sistema toyota de produção - assumem a forma de signos e imagens. Elas atuam como imagens de consumo e consumo de imagens e signos. Nesse caso, a imagem está ocupando o lugar de um discurso ideológico. Na instância do consumo, lócus crucial do processo de subjetivação, a manipulação através da imagem de marca, por exemplo, é uma nova forma de fetichismo que se dissemina à exaustão. Observa Otília Arantes:

\begin{abstract}
...o próprio ato de consumir se apresenta sob a aparência de um gesto cultural legitimador, na forma de bens simbólicos - como se disse à exaustão: de imagens ou de simulacros. É a forma-mercadoria no seu estágio mais avançado como forma-publicitária. O que se consome é um estilo de vida e nada escapa a essa imaterialização que tomou conta do social... a cultura tornou-se peça central na máquina reprodutiva do capitalismo, a sua nova mola propulsora (Arantes, 1998, citado por Fontenelle, 2002).
\end{abstract}

É importante salientar que, no caso do fordismo, o nexo psicofísico era constituído, segundo Gramsci, pela ideologia puritana e pela repressão sexual. No caso do toyotismo, o nexo psicofísico constitui-se, como salientamos ao tratarmos das inovações sócio-metabólicas, pela disseminação de valores-fetiches, expectativas e utopias de mercado e pela liberação dos instintos, ao mesmo tempo que se preserva a disciplina da vida industrial (o que é um poderoso agente estressor). Talvez, como iremos salientar mais adiante, o estressamento da corporalidade viva seja estratégia defensiva das individualidades de classe cindidas à exaustão pelos novos processos de subjetivação do capital.

\title{
As instâncias do psiquismo humano
}

Iremos apresentar algumas considerações, a título de hipóteses, sobre o modo de operação das instâncias psíquicas no processo de "captura" da subjetividade do trabalho vivo pelo capital como sistema de controle sócio-metabólico. Em primeiro lugar, é importante salientar que as instâncias do psiquismo humano não são meras estruturas instintivas do indivíduo, como o freudismo vulgar poderia supor. Existe uma dialética entre natureza e civilização, uma dinâmica biológica e, ao mesmo tempo, histórica, que constitui a anatomia da personalidade humana. As categorias freudianas dizem respeito menos à natureza pura (pelo que poderíamos acusá-las de "biologismo") e mais a uma segunda natureza, uma história cristalizada. Observa Jacoby (1977): "O que cria no indivíduo sua segunda natureza é apenas a história acumulada e sedimentada: uma história entorpecida, por ter sido tão prolongadamente não-liberada e uniformemente opressiva. A segunda natureza não é simplesmente natureza ou 
história, é a história cristalizada que se afigura como natureza”. Desse modo, consciência, préconsciência e inconsciente, em uma ótica dialético-materialista, possuem um caráter intrinsecamente histórico, tendo em vista que dizem respeito a modos de operar (e a relações) histórico-societais do psiquismo humano diante do mundo exterior (de si e dos outros, isto é, pessoas e objetos).

A instância psíquica do inconsciente que, na aparência, comporia-se de "pulsões arcaicas", seria, em si mesma, o indicador de uma situação social reificada. Em uma carta publicada por Ernst Jones, Freud escreveu: "Toda barreira interna do recalcamento é o resultado histórico de uma barreira externa. Portanto, é a internalização das resistências: a história da humanidade está depositada nas atuais tendências inatas ao recalcamento" (Jacoby, 1977).

Por outro lado, não podemos identificar as instâncias do psiquismo humano com substâncias, coisas ou mesmo lugares, ou seja, um lugar substancial, anatômico e corporificável. Consciência, pré-consciência e inconsciente dizem respeito a modos de operação do psiquismo humano e formas de relações sociais de ordem simbólica diante do mundo exterior. Muitas vezes, a utilização de metáforas na descrição das operações das instâncias psíquicas pode nos levar a substancializá-las. A utilização por Freud da concepção tópica, com seus "lugares psíquicos", contribuiu para essa substancialização. Entretanto, é importante ressaltar que consciência, pré-consciência ou inconsciente não são lugares anatômicos, reais ou análogos, por exemplo, aos cômodos de um apartamento. Diz Garcia-Roza (2004):

O termo "conteúdo do inconsciente" não designa uma relação de conteúdo análoga a quando dizemos que o copo contém água. Dizer que uma representação é inconsciente ou que está no inconsciente não significa outra coisa senão que ela está submetida a uma sintaxe diferente daquela que caracteriza a consciência. O inconsciente é uma forma e não um lugar ou uma coisa.

E salienta adiante:

Assim sendo, a cisão produzida na subjetividade pela psicanálise não deve ser entendida como a divisão de uma coisa em dois pedaços, mas como uma cisão de regimes, de formas, de leis (...) o que define, portanto, o inconsciente não são os seus conteúdos, mas o modo segundo o qual ele opera, impondo a esses conteúdos uma determinada forma (Garcia-Roza, 2004, grifos nossos).

\section{A pré-consciência}

Na sua obra clássica O princípio esperança, o filósofo marxista Ernst Bloch tratou da "pré-consciência" como sendo o "ainda-não-consciente". É como iremos considerar a instância psíquica da pré-consciência. Apesar de incorporar o léxico freudiano, Bloch diverge da interpretação de Freud sobre o valor heurístico das instâncias psíquicas da pré-consciência e do inconsciente, além de elaborar uma outra psicologia das pulsões (para Bloch, por exemplo, a pulsão da fome é a pulsão fundante e fundamental do homem, em vez da pulsão sexual, como considerou Freud). Segundo Bloch, o inconsciente freudiano "cerca a consciência como se fosse um anel", estando "fixado na escuridão e fechado em relação ao futuro" (Bloch utiliza-se de metáforas para descrever o modo de operação do inconsciente). Para ele, só a préconsciência é capaz de romper esse fechamento (ou cerco) do inconsciente. A pré-consciência é uma "nova classe de consciência", que representa a camada da vida psíquica capaz de produzir um "sonhar para a frente", indicando "algo futuro" ou "vindouro" (Bloch, 2005).

O "conteúdo" da instância do pré-consciente, apesar de não estar presente na consciência, continua acessível a ela, diversamente dos "conteúdos" do sistema inconsciente. O 
inconsciente seria o "não-mais-consciente", isto é, aquilo que caiu em uma "camada profunda" da psique, ficando depositado, segundo Bloch, em uma espécie de "paisagem lunar da perda cerebral", passando a representar o resto esquecido da psique (e que nem por isso é menos importante) (Bloch, 2005). Para Arno Munster (1997), o "ainda-não-consciente" de Ernst Bloch está para o "inconsciente" de Freud como o "sonho diurno" está para os "sonhos noturnos". Bloch destaca a importância do "sonho diurno", que é, segundo ele, a porta, o critério e o sintoma principal para a determinação da classe de consciência do "ainda-nãoconsciente". A pré-consciência para ele "representa o espaço propriamente dito da disponibilidade para o novo e a produção do novo". Os sonhos diurnos são, em sua estrutura básica, "sonhos para a frente", isto é, carregados com "conteúdos" da consciência e com material proto-utópico, que cintila do interior do futuro (Bloch, 2005; Munster, 1997).

$\mathrm{Na}$ condição de imagens prenunciadoras do utópico que se manifestam na consciência, os "sonhos diurnos" da pré-consciência são conteúdos da consciência de algo futuro/vindouro e, ao mesmo tempo, momentos desencadeadores da produtividade criadora. Por isso, a instância da pré-consciência é um campo fértil de "captura" pelo capital em processo, que visa não apenas a se legitimar, mas espoliar as riquezas ampliadas da subjetividade complexa. Ora, a subjetividade do trabalho vivo é produto irremediável do desenvolvimento do processo civilizatório humano-genérico. Disse-nos William Shakespeare, pelo seu personagem Laertes, em Hamlet: "Pois a natureza não nos faz crescer apenas em forças e tamanho. À medida que este templo se amplia, se amplia dentro dele o espaço reservado para a alma e para a inteligência". Por trás da ampliação do "templo" da alma humana, como a instância da préconsciência, com seus sonhos diurnos e momentos desencadeadores da produtividade criadora, sede dos construtos utópicos, está o processo de desenvolvimento das capacidades produtivas do trabalho social que amplia "o espaço reservado para a alma e para a inteligência". Entretanto, o processo civilizatório, que ocorre no interior do desenvolvimento do capital, é intrinsecamente contraditório. Na medida em que se desenvolve o espaço da subjetividade (e as formas de subjetivação e de constituição da individualidade moderna), o sujeito e os espaços da subjetividade são irremediavelmente negados, invertidos e obliterados pelas relações sociais capitalistas de produção da vida social. Na verdade, o capital desenvolve e amplia o templo da alma humana para dele se apropriar e espoliar, como no caso da pré-consciência, "capturando" os sonhos diurnos, e como diz Ernst Bloch (2005): "os modos da 'consciência-ainda-não' no arco antecipatório que liga matéria e utopia".

Então, o "sonho para frente" do capital e suas expectativas e utopias de mercado são meras reiterações da coação exterior, incapazes de sair de algo e de sair da própria imaturidade e do cárcere do sócio-metabolismo estranhado imerso em valores-fetiches. Portanto, ao ampliar o "templo" da subjetividade humana, o capital expressa uma potencialidade contraditória de si, desde que se constituiu como sistema de controle sócio-metabólico. Ao ampliá-la, ele se apropria das capacidades físicas e espirituais da corporalidade viva. Entretanto, como "contradição viva", sua forma social é incapaz de conter o conteúdo ampliado da humanidade obliterada (eis o que Marx traduziu por meio da contradição entre desenvolvimento das forças produtivas e relações sociais de produção).

\section{O inconsciente}

Freud não foi o primeiro pensador a descobrir o inconsciente ou a inventar essa palavra para defini-lo. No entanto foi ele, sem dúvida, que acabou por incorporar o conceito em uma nova ciência da alma humana: a psicanálise. Roudinesco diz-nos que "com Freud o inconsciente deixou de ser uma 'supraconsciência' ou um 'subconsciente', situado acima ou além da consciência, e se tornou realmente uma instância a que a consciência já não tem acesso, mas que se revela a ela através do sonho, dos lapsos, dos jogos de palavras, dos atos falhos etc." (Roudinesco \& Plon, 1998). 
Pouco antes de Freud, Theodor Lipps, professor de psicologia em Munique, autor do livro Os fatos fundamentais da vida psíquica (1883), tratara do conceito de inconsciente, considerando que todos os processos psíquicos seriam inconscientes. Além disso, ainda no século XIX, o século do capitalismo industrial, o romantismo alemão concebera um inconsciente descritivo, que Eduard Von Hartman (1842-1906) descrevera em seu livro Filosofia do inconsciente, lançado em 1868. O que se constata é que, no esteio do desenvolvimento da civilização burguesa, emerge, com vigor, a noção de inconsciente e com Sigmund Freud ela assume um estatuto categorial original.

Consideramos que o conceito de inconsciente em Freud é uma categoria intrinsecamente histórica, que surge a partir da análise das formações psicopatológicas da vida cotidiana e do sonho na civilização burguesa. É da análise perspicaz do metabolismo social do mundo burguês que o pensador austríaco construiria a interpretação psicanalítica. A partir de então, Freud concebeu uma sofisticada teoria do inconsciente em que distingue dois tipos de inconscientes, ambos inconscientes no sentido descritivo, porém muito diferentes quanto à sua dinâmica e quanto ao futuro de seus conteúdos: primeiro, o inconsciente propriamente dito, de que estamos tratando agora, e que nunca poderia chegar à consciência; segundo, o préconsciente, de que tratamos na seção anterior e cujos conteúdos podem atingir a consciência sob certas condições, em especial após o controle de uma espécie de censura.

O inconsciente em Freud não é o inverso do consciente ou como uma "segunda consciência". Para Freud, deve ser concebido como um sistema que possui conteúdos, mecanismos e talvez, uma "energia" específica. Segundo Laplanche e Pontalis (2000), Freud resume o inconsciente como sistema com as seguintes características específicas: processo primário (mobilidade dos investimentos, característica da energia livre); ausência de negação, de dúvida, de grau de certeza; indiferença perante a realidade e regulação exclusiva pelo princípio de desprazer-prazer (visando a restabelecer pelo caminho mais curto a identidade de percepção).

Não nos compete tratar aqui da teoria freudiana do inconsciente, mas apenas indicar algumas de suas características que podem nos sugerir elementos para apreendermos os mecanismos de "captura" da subjetividade do trabalho vivo pela ordem sócio-metabólica do capital.

\section{Origens do "inconsciente"}

Segundo Freud, o inconsciente seria uma instância psíquica constituída por "conteúdos" recalcados. Retornemos à carta publicada por Ernest Jones, em que Freud escreveu: "Toda barreira interna do recalcamento é o resultado histórico de uma barreira externa. Portanto, é a internalização das resistências: a história da humanidade está depositada nas atuais tendências inatas ao recalcamento". Nesse momento, o pensador austríaco vincula a barreira interna do recalcamento, que está na origem dos conteúdos do inconsciente, com o resultado histórico de uma barreira externa. Pode-se afirmar que o inconsciente é uma categoria ontogenética do homem com um conteúdo radicalmente histórico. A instância do "inconsciente" surge da luta do homem contra a escassez e da luta pela existência do animal homem pelo trabalho, que tem lugar em um mundo hostil.

$\mathrm{Na}$ ontologia do ser social, Lukács observa que nas circunstâncias de escassez, "os homens são impelidos pelas circunstâncias a agir de determinado modo 'sob pena de se arruinarem'. Eles devem, em última análise, realizar por si as próprias ações, ainda que freqüentemente atuem contra sua própria convicção" (itálicos nosso). O pensador húngaro prossegue analisando a anatomia da práxis social. Diz ele que "de fato, existem inúmeras 
situações nas quais, sob pena de se arruinar, é absolutamente necessário que o homem aja embora tenha clara consciência de não poder conhecer senão uma parte mínima das circunstâncias" (itálicos nossos). A práxis social do trabalho possui, desse modo, uma ampla margem de desconhecimento, com o homem dominando uma pequena faixa de elementos circundantes. É uma condição sócio-ontológica da práxis social. Apesar disso, como salienta Lukács, "o carecimento urge e, mesmo nessas condições, o trabalho promete satisfazê-lo, que ele, de qualquer modo, é capaz de realizá-lo" (Lukács, 1978).

Entretanto, observa Lukács, o desenvolvimento civilizatório e o aperfeiçoamento da atividade do trabalho (que se torna cada vez mais variado, abarcando campos cada vez maiores, subindo de nível tanto em extensão quanto em intensidade) não eliminam o fato de fundo, que constitui o fundamento ontogenético do "inconsciente" humano, ou seja, segundo ele, "a incognoscibilidade do conjunto das circunstâncias", o modo de ser do trabalho, que, paralelamente ao seu crescimento, como salienta o pensador húngaro, "desperta também a sensação íntima de uma realidade transcendente, cujos poderes desconhecidos o homem tenta de algum modo utilizar em seu próprio proveito" (Lukács, 1978).

Portanto, o "inconsciente" como categoria intrapsíquica é, em si, um elemento constitutivo do processo da práxis humana do trabalho e do processo de objetivação/exteriorização do homem como ser genérico que "não pode eliminar o fato de fundo, ou seja, a incognoscibilidade do conjunto das circunstâncias". Ele não é meramente a instância mental do sujeito humano constituída pelo recalcado e reprimido, como salientou Freud. Em sua dimensão filogenética, o inconsciente constitui-se pelo "desconhecido". É nas circunstâncias de uma sociedade de classe e sociedade mercantil complexa que o inconsciente interverte-se na instância mental do estranhamento ou do objeto que se tornou coisal (como observa Marx, 2004, nos Manuscritos de 1844). O "desconhecido" interverte-se naquilo que se é levado a "ignorar". Desse modo, pode-se dizer que é o inconsciente que constitui, no plano da subjetivação, as formas-fetiches. Diz Freud que a "representação inconsciente é a representação da coisa" (Freud, 2006). Diríamos nós, coisa-objeto em sua origem primordial, mas hoje, na sociedade das mercadorias, coisa-fetiche.

$\mathrm{Na}$ ótica histórico-materialista, o que institui (e constitui) o sujeito, no sentido de "sujeito sujeitado" (utilizando a acepção mais antiga do termo "sujeito", isto é, subjectus, que significa arremessado/lançado embaixo [sub] de algo ou de alguém) é, no sentido ontogenético, a natureza primordial ou o mundo hostil e exterior que aparece como "desconhecido". Por outro lado, no sentido sócio-histórico, é o controle sócio-metabólico do capital e o trabalho alienado que constituem (e instituem) um mundo social hostil e estranho ao ser genérico do homem. No princípio, o inconsciente aparece como o que assujeita o sujeito primitivo e como aquilo (o id) que o sujeito primitivo "desconhece". Entretanto, na sociedade burguesa, a sociedade das mercadoria imersas em fetichismos, o homem não apenas "desconhece" o que o assujeita, mas é levado a "ignorá-lo" (Lacan, 1999).

O psicanalista Jacques Lacan distingue entre "desconhecimento" e "ignorância". Segundo ele, o desconhecimento tem um compromisso com a verdade, isto é, com o conhecimento, e é constituído a partir deste último (para Agostinho, por exemplo, o desconhecimento é a presença de uma ausência). A ignorância, pelo contrário, é o vazio. O que significa que a instância intrapsíquica do inconsciente que surge na sociedade do capital possui um "compromisso" com a "ignorância" e não com o "desconhecimento", sendo mobilizado pelos aparatos do poder e do dinheiro para negar o sujeito e não para afirmá-lo (Lacan, 1999). Desse modo, parafraseando Freud, diríamos que "a representação inconsciente é a representação do fetiche”. É por ele que se constituem os processos de subjetivação estranhada da nova hegemonia do capital. 


\section{Mecanismos internos do inconsciente}

O que define o inconsciente não são os seus conteúdos, mas o modo segundo o qual ele opera, impondo a esses conteúdos uma determinada forma. Como já salientamos, o inconsciente é uma dimensão operativa intrínseca da práxis social do trabalho do homem como ser genérico. Ele surge da "incognoscibilidade do conjunto das circunstâncias" que caracteriza a atividade do trabalho. Lacan salientou que só há o inconsciente se houver o simbólico (Lacan, 1999). Mas diríamos também que, só há o simbólico porque há o trabalho como atividade social a partir da qual o animal homem faz-se homem. Como salientamos, é o "desconhecido" que produz o inconsciente. Entretanto, nas sociedades de classe, o "desconhecido" interverte-se no "recalcado". Por isso, a psicanálise, como a "economia política da subjetividade burguesa", colocou o inconsciente como produto do recalcamento.

O conceito de inconsciente designa uma função simbólica que se reduz a um conjunto de leis. Não iremos tratar dessas leis do inconsciente, mas somente de alguns aspectos que podem contribuir para a explicação dos mecanismos internos da "captura" da subjetividade pelo capital como sistema de controle sócio-metabólico. Num primeiro momento, ao salientarmos o inconsciente como uma função simbólica, indicamos um ponto essencial: é no campo do simbólico que ocorre a "captura" da subjetividade, como verificamos ao tratarmos do "imperialismo simbólico" no tocante às inovações sócio-metabólicas do capital. O acesso ao simbólico é a condição necessária para a constituição do inconsciente e, claro, também do consciente. No aspecto ontogenético do homem, inconsciente e consciente se formam por efeito de um mesmo ato. É a aquisição da linguagem que permite o acesso ao simbólico e a conseqüente clivagem da subjetividade (Garcia-Roza, 2004).

É importante salientar, entretanto, que a linguagem é instrumento do consciente e não do inconsciente. A linguagem está restrita ao campo do pré-consciente-inconsciente. Segundo Freud, o inconsciente é constituído sobretudo de representações imagéticas. Diz ele:

A representação (Vorstellung) consciente abrange a representação da coisa mais a representação da palavra que pertence a ela, ao passo que a representação inconsciente é a representação da coisa apenas. O sistema Ics (Inconsciente) contém as catexias da coisa dos objetos, as primeiras e verdadeiras catexias objetais; o sistema Pcs (Pré-consciente) ocorre quando essa representação da coisa é hipercatexizada através da ligação com as representações da palavra que lhe correspondem (Freud, 2006).

Ora, o mundo burguês é um mundo de objetos, objetos que se tornaram coisas, isto é, coisas-mercadorias que são fetiches, fetiches que são representações imagéticas que se impõem como coerção exterior às individualidades de classe. Anselm Jappe (1999) observa que a predominância da imagem (melhor dizendo, da "forma-imagem como desenvolvimento da forma-valor") indica uma radicalização do fetiche - o que faz ganhar atualidade a definição de Guy Debord sobre a imagem como forma final da reificação da mercadoria (Debord, 1997; Jappe, 1999). Para Marx, o fetichismo da mercadoria é a forma-fetiche relativamente mais simples. O mundo do capital é constituído por múltiplas formas-fetiches, com destaque para o fetichismo do dinheiro, por meio do qual o enigma do fetichismo da mercadoria torna-se visível e ofuscante, e o fetichismo do Estado ou, ainda, o fetichismo da técnica. A sociedade burguesa ou a sociedade das mercadorias é permeada por valores-fetiches que movem as individualidades de classe em suas escolhas existenciais. É por eles que ocorre a construção das implicações subjetivas ou o que salientamos como inovações sócio-metabólicas. As inovações sóciometabólicas operam a disseminação de valores-fetiches adequados à constituição de novos consentimentos espúrios. O que significa que a "captura" da subjetividade opera não apenas pela linguagem, instrumento do sistema pré-consciência-consciência, mas pelas representações das coisas. Na linguagem psicanalítica, as representações podem ser representações de coisas, essencialmente visuais, e representações de palavras, essencialmente acústicas. O inconsciente 
é constituído apenas por representações de coisas, ficando a representação de palavras e o afeto restrito ao sistema pré-consciente-consciente.

A título de ilustração, poderíamos descrever o modo de operação intrapsíquico do medo de desemprego, um dos afetos que se disseminam nas condições históricas do sóciometabolismo da barbárie. É o sistema pré-consciência/consciência que mobiliza, nas individualidades de classe proletária, o medo do desemprego (ou da precarização do trabalho), um dos afetos regressivos da alma humana. A representação consciente do desemprego abrange a representação do afeto (medo) mais a representação da palavra (desemprego) no plano do sistema pré-consciência/consciência. Por outro lado, em sua representação inconsciente, opera apenas a representação da coisa, isto é, apenas o significado "desemprego" aparece como coisa ou imagem-fetiche, representação imagética da desefetivação do ser genérico do homem. A mente inconsciente possui algumas características salientadas por Freud no livro, de 1915, O inconsciente (Freud, 2006). Uma delas é que algo meramente imaginário tende a ser percebido como real. O modo de operação mental do inconsciente substitui a realidade externa pela psíquica. Por isso, a manipulação do imaginário pelas imagens-fetiches do desemprego em massa é um dos elementos cruciais da "captura" da subjetividade. A emulação pelo medo é uma dos modos espúrios de construção dos consentimentos nos locais de trabalho. Por isso, o desemprego em massa possui uma função psicológica (ou simbólica) na sociedade do capital: criar as condições psíquicas para a "captura" da subjetividade do trabalho ${ }^{3}$. Na instância intrapsíquica do inconsciente, o desemprego aparece como objeto de pavor, coisa atemporal, ahistórica, quase natural, cuja imagem-condensação tende a reunir muitos significados diferentes. Uma outra característica da mente inconsciente é a atemporalidade. O inconsciente é atemporal, seus conteúdos não somente não estão ordenados no tempo, como não sofrem a sua ação desgastante. A temporalidade é exclusiva do sistema pré-consciência-consciência.

Outra característica do inconsciente, segundo Freud, é a isenção de contradições mútuas. O princípio da não-contradição não funciona no nível do sistema inconsciente. No inconsciente não há lugar para a negação. Observa Garcia-Rosa:

No sistema inconsciente, podem coexistir, lado a lado, duas representações contraditórias, sem que isso implique a eliminação de uma delas. Se dois desejos são incompatíveis do ponto de vista da consciência, no nível inconsciente eles não se eliminam, mas se combinam para atingir seu objetivo (Garcia-Roza, 2004).

É interessante observar ainda que o sistema inconsciente é caracterizado, segundo Freud, por dois mecanismos básicos, que são o "deslocamento" e a "condensação", que podem ser considerados, de certo modo, elementos cruciais da linguagem da manipulação da subjetividade pelo controle sócio-metabólico do capital. Esses mecanismos apontados por Freud em A interpretação dos sonhos como responsáveis pela elaboração onírica, segundo Lacan, não se restringem aos sonhos, mas podem ser considerados mecanismos fundamentais do inconsciente em geral. A metáfora e a metonímia, segundo o pensador francês, vão nos fornecer a tópica desse inconsciente. Para Lacan, os processos metafóricos e metonímicos são encontrados em funcionamento em todas as chamadas formações do inconsciente e são eles os responsáveis por uma das mais importantes características da linguagem: o seu duplo sentido, isto é, o fato de ela dizer outra coisa diferente daquilo que diz a letra (Lacan, 1999). Como observou Roman Jakobson, do ponto de vista da lingüística, esse efeito de alteração do sentido é obtido na metáfora, pela substituição de significantes que apresentam entre si a relação de similaridade, e na metonímia, pela substituição de significantes que mantêm relações de contigüidade

\footnotetext{
3 Isleide Fontenelle observa que, nos anos de 1940, Theodor Adorno já procurava pensar no processo ideológico da perspectiva de sua relação com a estrutura psíquica, tomando-a como a "mediação entre a ideologia e a sociedade". Foi a partir desse novo ponto de vista que Adorno propôs-se a pensar "nas configurações psicológicas" que sustentam o processo ideológico em um determinado momento histórico para que, a partir daí, pudesse ser analisado o "problema teórico da relação entre condições econômicas, produtos culturais e mudanças na estrutura psíquica dos indivíduos” (Carone, 1991, citada por Fontenelle, 2002, p. 292).
} 
(Jakobson, 2001). Por isso, na representação literária clássica da manipulação onisciente - o big brother do livro 1984 de George Orwell -, "paz é guerra" e "liberdade é escravidão". Além disso, o discurso da literatura de auto-ajuda empresarial usa e abusa de metáforas e metonímias, operações lingüísticas capazes de mobilizar o sistema inconsciente. O sentido da racionalidade cínica que marca o espírito do toyotismo possui elementos lingüísticos próprios das formações do inconsciente.

\section{O "inconsciente estendido"}

Freud observa que "o sistema inconsciente contém as catexias das coisas dos objetos, as primeiras e verdadeiras catexias objetais" (Freud, 2006). Na linguagem freudiana, catexias são investimentos de energia psíquica ligada a objetos externos. A sociedade de mercadorias, permeada de intensos apelos de propaganda e marketing, exige das individualidades de classe, a ocupação (ou catéxis) contínua das energias psíquicas nos objetos externos que aparecem como coisas. Na medida em que a sociedade das mercadorias é a sociedade das formas-fetiches e de objetos externos tornados coisas, ela impõe aos sujeitos humanos um determinado modo de operação da subjetividade e, portanto, um determinado processo de subjetivação que implica o que iremos denominar de "alargamento" do inconsciente. É o "inconsciente estendido" que caracteriza a sociedade burguesa tardia, marcada pelos fenômenos da reificação (utilizando a metáfora de Bloch, diríamos que, numa sociedade hiperfetichizada, o inconsciente é como um "anel que cerca a consciência (...) fixado na escuridão e fechado em relação ao futuro"). Por isso, os medos das individualidades de classe do século XXI tendem a ser "medos fetichizados", ou melhor, "medos reificados" e, portanto, racionalizados: medos intensos de uma subjetividade complexa obliterada pelas relações sociais de produção capitalista. Por isso, eles (os medos) são catalisadores do estresse, doença crônica da sociedade do toyotismo.

O "alargamento" da instância do inconsciente ou a constituição do "inconsciente estendido", que ocorre nas condições do capitalismo global, é um dos pressupostos de negação da atividade praxeológica, consciente e racional do homem. Na medida em que se agudizam o fetichismo da mercadoria e a reificação, o inconsciente estende-se, tornando-se o pressuposto irremediável do sócio-metabolismo da barbárie. Marcuse observa, por exemplo, uma das implicações políticas da teoria freudiana: "As transformações fundamentais na sociedade industrial são acompanhadas de transformações igualmente fundamentais nas estruturas psíquicas primárias" (Marcuse, 1998).

Desse modo, o inconsciente do homem burguês possui a legalidade de uma sociedade histórica de classe, sociedade mercantil complexa em que a condição de classe e de proletariedade, da força de trabalho como mercadoria e do trabalho vivo subsumido às condições objetivas do capital, incorporam-se, no decorrer do desenvolvimento histórico moderno, como sendo a verdadeira condição do inconsciente. Na medida em que se amplia o espectro do fetichismo da mercadoria e dos múltiplos fetichismos da ordem do capital, com a disseminação das relações mercantis, o inconsciente como instância do psiquismo humano tende a tornar-se mais denso e profundo. É por meio desse "inconsciente estendido" que a ordem sócio-metabólica do capital constitui o tráfico dos consentimentos dominantes. É do seu "alargamento" que provêm as imagem-fetiches que compõem as sintomatologias das "novas doenças da alma" diante de um precário mundo do trabalho.

O inconsciente é elemento compositivo do processo de subjetivação do fetichismo da mercadoria. A forma-mercadoria é a síntese estrutural do modo de ser social sob o capitalismo. Para compreender como se dá o processo da ideologia, Jean Baudrillard, por exemplo, parte da teoria do fetichismo da mercadoria em Marx, que, segundo ele, está "não na projeção de uma 
consciência alienada nas superestruturas, mas na própria generalização, a todos os níveis, de um código estrutural". Trata-se, segundo o autor, antes da "paixão do código" do que de objetos como "instâncias reificadas, dotadas de força e de mana, nas quais o sujeito se projeta e aliena". É desse código generalizado de signos "e de modo nenhum do... valor de uso [dos objetos], nem de suas virtudes infusas, que vem o fascínio que eles exercem” (Baudrillard, 2007).

Na sociedade capitalista esse código é o "valor de troca", em que todas as relações sociais são mediadas e, enquanto ele persistir, seria uma grande ilusão acreditar que se poderia restituir às mercadorias o seu valor de uso ou tornar transparente a relação dos homens com as suas "necessidades", porque é a própria "forma da relação social" que impossibilita essa passagem. Por isso, como observa Fontenelle, o fetichismo da mercadoria deveria ser compreendido como o fascínio (ambivalente) de uma forma (lógica da mercadoria ou sistema do valor de troca)... algo como um desejo perverso, o "desejo do código". Na psicanálise, o fetichismo, um "desejo perverso", está ligado a uma "estrutura perversa" - o inconsciente burguês, instância constitutiva de todo o desejo. O fetichismo da mercadoria (que, segundo Marx, "é a forma mais geral e menos desenvolvida da produção burguesa") seria o ponto em que convergem a economia mercantil e a economia psíquica do valor (Fontenelle, 2002). Na verdade, o fetichismo da mercadoria e seus mecanismos inconscientes impregnam todas as objetivações sociais - inclusive imagens, signos e valores, constituindo o que denominamos as formas-fetiches. Desse modo, o "inconsciente estendido" torna-se a matéria psíquica das formas-fetiches que se disseminam na sociedade burguesa tardia.

Por outro lado, na medida em que os processos da mente inconsciente são atemporais (as idéias não são ordenadas cronologicamente e não se alteram com a passagem do tempo) (Mollon, 2005), eles tendem a constituir uma das principais características das formas-fetiches, isto é, a negação da memória e do passado histórico. Por isso, para Adorno e Horkheimer, "a luta contra o fetichismo é a luta contra o esquecimento". Walter Benjamin observa que o exercício da rememoração (eingedenken) ensina a estabelecer com o passado uma relação viva. É claro que a "rememoração" é impotente para libertar-nos dos grilhões do presente (só a revolução pode fazê-lo), porém desempenha um papel fundamental no resgate libertador do que aconteceu, do que poderia ter acontecido (Benjamin citado por Konder, 2005). Adorno e Horkheimer (1985) diriam: “...não se trata de conservar o passado, mas de recuperar as esperanças pretéritas” (Adorno \& Horkheimer, 1985).

É a vigência do "inconsciente estendido" que explica um dos fenômenos mais característicos e lúgubres do final do século XX: a destruição do passado, ou melhor, dos mecanismos sociais que vinculam nossa experiência pessoal à das gerações passadas. Diz Eric Hobsbawn: "Quase todos os jovens de hoje crescem numa espécie de presente contínuo, sem qualquer relações orgânicas com o passado público da época em que vivem" (Hobsbawn, 2001). ${ }^{4}$

Os elementos do pré-consciente são capazes de romper o fechamento presente do inconsciente. Entretanto, a ordem sócio-metabólica do capital tende a incorporar também a pré-consciência, isto é, "capturar" a zona do "despertar" como "simulacro" de futuro, cujos "sonhos diurnos" afirmam-se e amesquinham-se ao mesmo tempo em suas pretensões mercantis. É da instância da pré-consciência que se disseminam expectativas e utopias de mercado, um "algo futuro" e vindouro que tende a ser mera reiteração do presente. $\mathrm{Na}$ verdade, é da pré-consciência que o capitalismo de consumo de massa e da contingência salarial retira (e elabora) suas imagens (as "marcas") fugazes e fluidas do lugar do "novum" (Fontenelle, 2002). Desse modo, a manipulação da subjetividade é, acima de tudo, não apenas

\footnotetext{
4 A deterioração da memória coletiva é um fenômeno social que possui implicações em nossa capacidade de imaginar experiências futuras. A imersão no "presente contínuo" significa não apenas a destruição do passado, mas a deterioração da capacidade de construir cenas futuras e eventos imaginários. Por exemplo, pesquisadores ingleses, liderados por Eleanor Maguirre, publicaram um trabalho na revista Proceeding of the National Academy of Sciences demonstrando que os mesmos circuitos de neurônios ativados para lembrarmos do passado são colocados em funcionamento para construirmos imagens do futuro (Hassabis et al., 2007).
} 
a manipulação do inconsciente, mas a manipulação dos "sonhos diurnos" e da "zona" de despertar de homens e mulheres proletários. Na pré-consciência as possibilidades do futuro aparecem diretamente em imagem. Por isso, o sistema do capital, que busca "travar" a futuridade em prol da reiteração constante do presente, isto é, da acumulação de valor abstrato, é, hoje mais do que nunca, um sistema social de produção de imagens, imagens que carregam livremente o desejo, assumido ao nível da consciência.

As imagem-fetiches são imagens de consumo e desejo de mercadorias. Imagensalegorias que reiteram a ordem sócio-metabólica do capital. Aliás, a propaganda e o marketing usam (e abusam) de imagem-alegorias, isto é, imagens que, como metáforas do mecanismo de deslocamento do inconsciente, dizem uma coisa sabendo-se que significam outra. $\mathrm{O}$ recurso à alegoria, como observou Walter Benjamin, é-nos imposto pelas condições históricas em que nos encontramos. Para ele, somos sobreviventes de uma destruição paulatina de todos os grandes valores antigos, que foram aviltados e transformados em escombros pela mercantilização da vida: "As alegorias são, no reino dos pensamentos, o que as ruínas são no reino das coisas" (Benjamin, 1995).

Desse modo, a nova ordem neoliberal busca disseminar, pelos aparatos midiáticos e suas imagem-alegorias de desejos, sonhos exclusivamente individuais, desejos de mercado, utopias ideológicas, em que se sonha possuir uma casa transbordante de quinquilharias eletrônicas. Por isso, as inovações sócio-metabólicas buscam disseminar uma imaginação utópica do mercado pelas marcas que carregam desejos de consumo e que simulam, como elementos fictícios, "viradas no tempo", tempos de "aurora" ou mesmo "juventude", utilizando as expressões de Bloch.

\section{A compressão psicocorporal}

Não apenas a mente, mas também o corpo é elemento compositivo da subjetividade humana, que se torna campo de luta da "captura" da subjetividade do trabalho pelo capital. Iremos apresentar algumas hipóteses sobre a relação corpo-mente e sua nova dinâmica sob a "acumulação flexível" e a lógica sócio-reprodutiva do capitalismo global. Nossa hipótese de trabalho é que, sob o novo regime de "acumulação flexível", ocorre, pelo menos como promessa frustrada do capital, o que iremos denominar "compressão psicocorporal", que caracteriza o novo modo de articulação corpo-mente, tanto no processo de trabalho quanto no processo sócio-reprodutivo. O novo modo de articulação corpo-mente distingue-se daquele que predominava no sistema taylorista-fordista e que tendia, por exemplo, a "separar" mente e corpo. Como salientou Gramsci, sob o fordismo "o cérebro está livre para outras ocupações", enquanto o corpo é capturado pelas prescrições mecanizadas (Gramsci, 1984).

No contexto do fordismo-taylorismo ocorreu a decomposição da figura humana, ou do sujeito (e da subjetividade) do trabalho, tendo em vista que, no interior da linha de produção de mercadorias, o cérebro separou-se do corpo submetido às prescrições taylorista-fordistas. Por exemplo, o imaginário modernista do século XX expressou, de certo modo, segundo Moraes (2002), a implicação subjetiva problemática constitutiva da lógica taylorista-fordista através da idéia do "corpo impossível". Essa relação problemática entre corpo e mente seria um dos elementos de crise do fordismo-taylorismo nas décadas de 1960 e 1970.

Por outro lado, sob a produção toyotista, mente e corpo são mobilizados pelo capital para integrarem-se à produção do valor. A busca de uma nova implicação subjetiva na produção "pós-fordista" supõe uma nova relação corpo-mente, o que significa não apenas uma nova disposição psico-cognitiva, mas uma nova postura corporal ou nexo psicofísico capaz de recompor a subjetividade do trabalho vivo nas condições da acumulação flexível. Entretanto, a 
promessa do toyotismo de recompor a figura humana no interior da produção de mercadorias racionalizada é meramente virtual. É mais uma promessa frustrada do capital como sistema de controle sócio-metabólico, sendo meras espectralidades sociais, promessas irremediavelmente frustradas, sempre repostas como pressupostos negados do sistema produtor de mercadorias. A "compressão psicocorporal", ou o reencontro do corpo com o cérebro, o gesto físico flexível (ou melhor, espontâneo) e a negação da cisão da subjetividade são promessas frustradas do toyotismo. A "recomposição" mente-corpo que ocorre com o toyotismo é tão problemática quanto a decomposição mente-corpo que caracterizava o fordismo-taylorismo. Portanto, o que denominamos "compressão psicocorporal" é tão problemático quanto a suposta cisão corpomente, sendo expressão de uma contradição candente que dilacera a subjetividade do trabalho vivo (o que explica a disseminação das novas doenças da alma humana).

O dilaceramento da subjetividade do trabalho vivo decorre da frustração irremediável da promessa de politecnia pelo capital. $\mathrm{Na}$ verdade, as "potencialidades tecnológicas contraditórias" (Lojkine, 1995) colocadas pela Quarta Idade da Máquina, apesar de irremediavelmente frustradas pelas relações sociais de produção do capital, possuem plena efetividade no plano da representação imaginária dos sujeitos sociais. Elas seriam o "ainda-nãoser" que instigaria a dimensão pré-consciente do trabalho vivo. Em seu $O$ princípio esperança, Ernst Bloch fundaria uma "ontologia do ainda-não-ser", capaz de determinar de modo novo o ser, que passa a ser um "modo da possibilidade para a frente", estreitamente correlacionada, como diria Arno Münster, "com o conceito de antecipação como veículo formal da produção parcial das manifestações do utópico na realidade concreta hic et nunc" (Munster, 1997).

Portanto, o dilaceramento da subjetividade humana decorreria não apenas do inconsciente que, segundo Bloch, é como se fosse um anel que cerca a consciência, estando "fixado na escuridão e fechado em relação ao futuro", mas também da frustração irremediável das "possibilidades tecnológicas contraditórias" que habitariam um campo de determinação da classe de consciência do "ainda-não-consciente". Para Bloch, a consciência do "ainda-nãoconsciente" seria a camada ou instância até agora "não percebida" do inconsciente, que "representa o espaço propriamente dito da disponibilidade para o novo e para a produção do novo" (Bloch, 2005). Ao tratarmos das instâncias psíquicas da subjetividade humana, identificamos o "ainda-não-consciente", que é capaz de romper esse fechamento, com a instância da pré-consciência. É nela que Ernst Bloch identificará os "sonhos para frente", os conteúdos da consciência com material proto-utópico, constituído por imagens prenunciadoras do utópico.

A produção do capital nas condições da "acumulação flexível", ao constituir-se por meio da "captura" da subjetividade do trabalho, instaura um campo inédito de contradições sociais que colocam novas possibilidades de "negação da negação". Mesmo com seu estatuto precário, a subjetividade como instância da atividade prático-sensível do sujeito humano é constituída, em si, tanto pela personalidade mental quanto pela corporalidade viva. Essas são dimensões inalienáveis do sujeito, cuja separação é meramente heurística. Nas condições do trabalho estranhado, a desefetivação intrínseca à lógica do trabalho capitalista atinge as duas dimensões da subjetividade humana. As doenças do trabalho toyotizado são doenças psicossomáticas com impactos dilacerantes na instância psíquica e na corporalidade viva.

O fordismo-taylorismo constituiu tal "rigidez" na disposição mente-corpo da subjetividade do trabalho, que o toyotismo é obrigado a flexibilizar sob pena de não constituir o nexo psicofísico capaz de instaurar a nova forma de subsunção do trabalho vivo ao capital. A nova implicação subjetiva do corpo parece ser a última fronteira de subversão do capital. Por isso, o toyotismo constitui um tipo de "compressão psicocorporal", similar à "compressão espaço-tempo" constatada por David Harvey no livro Condição pós-moderna. Na verdade, a compressão psicocorporal é um elemento da experiência da condição pós-moderna, a experiência do corpo, instaurada pelo desenvolvimento de um novo regime de acumulação capitalista, a "acumulação flexível". É claro que as múltiplas mudanças nas experiências do 
espaço e do tempo, tratadas por Harvey no capítulo "A compressão do tempo-espaço e a condição pós-moderna", não poderiam deixar de ter rebatimentos nas experiências do corpo, tendo em vista que o corpo é elemento ineliminável do sujeito e, portanto, da subjetividade. Como diria Foucault, desde o surgimento da modernidade do capital, o corpo tornou-se objeto de "práticas subjetivadoras" da "sociedade disciplinar".

As transformações estruturais na dinâmica capitalista a partir de sua crise estrutural alteram as "práticas subjetivadoras" da sociedade do capital. É por elas que o sujeito pode pensar-se enquanto sujeito. É por meio das "práticas subjetivadoras", ao constituir sua relação com o trabalho, que o ser humano transforma-se em sujeito de si para si (o que Foucault denominaria de "técnicas de si"). Não existem apenas técnicas de produção, de comunicação ou de poder, existem também técnicas para voltar-se para si, as "tecnologias do eu" (Foucault, 1994). Na nova etapa do desenvolvimento capitalista, devido à instauração do novo regime de "acumulação flexível", com o desenvolvimento do toyotismo, alteram-se as "tecnologias do eu". Destacamos, neste caso, alterações da experiência do corpo, dimensão crucial do próprio self. Diz Foucault: "A relação entre a manipulação de objetos e a dominação aparece claramente em 'O Capital' de Karl Marx, em que cada técnica de produção exige uma modificação da conduta individual, exige não só aptidões, mas também atitudes" (Foucault, 1994).

Na etapa da "acumulação flexível", surge uma nova atitude problemática do sujeito para consigo mesmo, por meio da relação dele com seu corpo. Com o toyotismo, altera-se o tráfico corpo-mente, com a nova organização capitalista da produção dissolvendo a antiga atitude disciplinar que o corpo tinha no modo de organização taylorista-fordista. Na verdade, o corpo não se emancipa da disciplina do capital, mas se constitui uma nova relação psicocorporal, que busca preservar um componente essencial das sociedades do capital, sejam elas moderna ou pós-moderna: um corpo útil, produtivo e submisso. Por exemplo, a "compressão psicocorporal" pode ser constatada por meio das experiências de "ginástica laboral" nas empresas, nas quais a postura corporal (e, portanto, subjetiva) do trabalhador tende a tornar-se indispensável para a obtenção da produtividade nas condições sob o toyotismo (o toyotismo que, como salientamos, é administração by stress e administração by panoticum). O novo regime de "acumulação flexível" impõe o novo tráfico corpo-mente como meio de "administrar" o estresse que atinge o trabalhador assalariado nas condições de intensificação do trabalho estranhado. O que se observa é meramente o simulacro de emancipação do corpo-sujeito da disciplina do capital.

O espírito do toyotismo dissemina-se nas instâncias de reprodução social por meio dos valores-fetiches, expectativas e utopias de mercado. Por isso, no capitalismo flexível disseminam-se a corpolatria e as utopias do corpo. A "compressão psicocorporal" pode ser constatada pela proliferação do "culto ao corpo" ou de transgressões do imaginário do corpo como território indevassável (tatuagens e piercings não deixam de ser sintomas do devassamento do corpo como experiência psicocorporal problemática, como é o caso do toyotismo). A estética do modernismo tendia a separar corpo e mente. É curioso que, no plano estético, o romance fantástico Frankenstein, de Mary Shelley (1815), parece sugerir que a reconstituição do corpo nas condições do capitalismo industrial do século XIX, da grande indústria de base técnica rígida, tenderia apenas a produzir monstros, tão inflexíveis quanto autômatos desconjuntados. Enfim, o corpo impossível da estética modernista pressupunha um tipo de tráfico psicocorporal particular, que o fordismo-taylorismo traduziu, em sua tipicidade, como a separação corpo e cérebro.

Por outro lado, a estética do pós-modernismo tende a fundir corpo e mente no "homem pós-orgânico". O corpo é refundado por técnicas digitais e de virtualização (Sibilia, 2002). Desse modo, a "crise do fordismo" é também a crise de uma experiência do corpo útil, produtivo e submisso. É a crise de uma prática subjetivadora que precisava ser reconstituída segundo a lógica da acumulação flexível. Mas a reconstituição psicocorporal do toyotismo é deveras problemática. Se ela tende a fundir corpo e mente, ao flexibilizar o corpo rígido, 
tornando-o maleável para a nova subsunção do trabalho ao capital, ela não o emancipa, nem o poderia. De fato, o toyotismo, como salientamos, possui elementos de continuidade com o taylorismo e fordismo que impedem/subvertem a nova disposição/organização pressuposta no novo modo de subsunção que exige a base técnico-civilizacional que o toyotismo procura representar, sem consegui-lo, pois contém a perversão da utopia do trabalho.

\section{Referências}

Adorno, T. \& Horkheimer, M. (1985). Dialética do esclarecimento. Rio de Janeiro: Zahar.

Alves, G. (2000). O novo (e precário) mundo do trabalho: reestruturação produtiva e crise do sindicalismo. São Paulo: Boitempo.

Antunes, R. (1995). Adeus ao trabalho? Ensaio sobre as metamorfoses e a centralidade do mundo do trabalho. São Paulo: Cortez.

Antunes, R. (1999). Os sentidos do trabalho: ensaio sobre a afirmação e a negação do trabalho. São Paulo: Boitempo.

Antunes, R. (Org.) (2006). Riqueza e miséria do trabalho no Brasil. São Paulo: Boitempo.

Arantes, O. (1998). Urbanismo em fim de linha: e outros estudos sobre o colapso da modernização arquitetônika. São Paulo: Edusp.

Benjamin, W. (1995). A origem do drama barroco alemão. Lisboa: Relógio D'água.

Baudrillard, J. (2007). A sociedade de consumo. Lisboa: Edições 70.

Bloch, E. (2005). O princípio esperança (vol. 1). Rio de Janeiro: Contraponto.

Carone, I. (1991). De Frankfurt a Budapeste: os paradoxos de uma psicologia de base marxista. Psicologia USP, 2 $(1 / 2), 111-120$.

Debord, G. (1997). A sociedade do espetáculo. Rio de Janeiro: Contraponto.

Duning, J. H. (1988). Explaining international production. Londres: Unwin Hyman.

Freud, S. (2006). O inconsciente. In Obras psicológicas de Sigmundo Freud. Escritos sobre a psicologia do inconsciente. São Paulo: Imago.

Foucault, M. (1994). Dits et Écrits (vol. 4). Paris: Gallimard.

Fontenelle, I. A. (2002). O mome da marca: McDonald's, fetichismo e cultura descartável. São Paulo: Boitempo.

Garcia-Roza, L. A. (2004). Freud e o inconsciente. São Paulo: Zahar.

Gramsci, A. (1984a). Maquiavel, a política e o Estado moderno. Rio de Janeiro: Civilização Brasileira.

Gramsci, A. (1984b). Concepção dialética da história. Rio de Janeiro: Civilização Brasileira.

Harvey, D. (1990). Los limites del capitalismo y la teoria marxista. México: Fondo de Cultura Econômica.

Harvey, D. (1992). Condição pós-moderna: uma pesquisa sobre as origens da mudança cultural. São Paulo: Loyola.

Harvey, D. (2004). O novo imperialismo. São Paulo: Loyola.

Hassabis, D., Kumaran, D., Vann, S. D. \& Maguire, E. A. (2007). Patients with hippocampal amnesia cannot imagine new experiences. PNAS, 104 (5), $1726-1731$.

Hobsbawn, E. (2001). A era dos extremos. São Paulo: Paz e Terra.

Jacoby, R. (1977). Amnésia social: uma crítica à psicologia conformista, de Adler a Laing. Rio de Janeiro: Zahar.

Jakobson, R. (2001). Lingüística e comunicação. São Paulo: Cultrix.

Jameson, F. (1988). Pós-modernismo: a lógica cultural do capitalismo tardio. São Paulo: Ática.

Jappe, A. (1999). Guy Debord. Rio de Janeiro: Vozes.

Kosik, K. (1976). Dialética do concreto. Rio de Janeiro: Paz e Terra.

Konder, L. (2005). Os sofrimentos do homem burguês. São Paulo: Senac. 
Lacan, J. (1999). As formações do inconsciente (Seminário 5). Rio de Janeiro: Zahar.

Lojkine, J. (1995). A revolução informacional. São Paulo: Cortez.

Lukács, G. (1978). As bases ontológicas da atividade e do pensamento do homem. In Revista Temas de Ciências Humanas, 4, 1-18.

Lukács, G. (1981). Ontologia dell'essere sociale. Roma: Riuniti.

Marx, K. (1996). O capital: crítica da economia política (livro 1). Rio de Janeiro: Nova Cultural.

Marx, K. (1985). Capítulo VI inédito de O capital: Resultados do processo de produção imediata. São Paulo: Moraes.

Marx, K. (1983). Contribuição à crítica da economia política. São Paulo: Martins Fontes.

Marx, K. (2004). Manuscritos econômico-filosóficos. São Paulo: Boitempo.

Marx, K. \& Engels, F. (1998). Manifesto comunista. São Paulo: Boitempo.

Marcuse, H. (1998). Cultura e sociedade (vol. 2). São Paulo: Paz e Terra.

Mollon, P. (2005). O inconsciente: conceitos de psicanálise. Viver: Mente e Cérebro.

Moraes, E. (2002). O corpo impossível. São Paulo: Iluminuras.

Munster, A. (1997). Utopia, messianismo e apocalipse nas primeiras obras de Ernst Bloch. São Paulo: Unesp.

Mészáros, I. (2002). Para além do capital: rumo a uma teoria da transição. Campinas e São Paulo: Unicamp e Boitempo.

Mészáros, I. (2003). O século XXI: socialismo ou barbárie. São Paulo: Boitempo.

Laplanche, J. \& Pontalis, J. B. (2000). Vocabulário de psicanálise. São Paulo: Martins Fontes.

Roudinesco, E. \& Plon, M. (1998). Dicionário de psicanálise, Rio de Janeiro: Zahar.

Ruiz, E. (1998). Freud no divã do cárcere: Gramsci analisa a psicanálise. Campinas: Autores Associados.

Safatle, V. (2004). Sobre um riso que não reconcilia: ironia e certos modos de funcionamento da ideologia. Revista Margem Esquerda, 5, 131-146.

Sibilia, P. (2002). O homem pós-orgânico. Corpo, subjetividade e tecnologias digitais. São Paulo: Relume-Dumará.

Silveira, P. \& Doray, B. (Orgs.) (1989). Elementos para uma teoria marxista da subjetividade. São Paulo: Vértice.

Teixeira, F. J. S. (1999). O capital e suas formas de produção de mercadorias: rumo ao fim da economia política. Fortaleza. [mimeo]

Teixeira, A. (1998). Trabalho, tecnologia e educação: algumas considerações. Cadernos do Centro de Estudos e Ação Social, 177, 25-40.

Zaretsky, E. (2006). Segredos da alma: uma história sociocultural da psicanálise. São Paulo: Cultrix.

Zizek, S. (2003). Fétichisme et subjetivation interpassive. Actuel Marx, 34, 99-109.

\section{Endereço para correspondência \\ giovani.alves@uol.com.br}

Recebido em: 04/04/2008

Revisado em: 07/05/2008

Aprovado em: 04/06/2008 